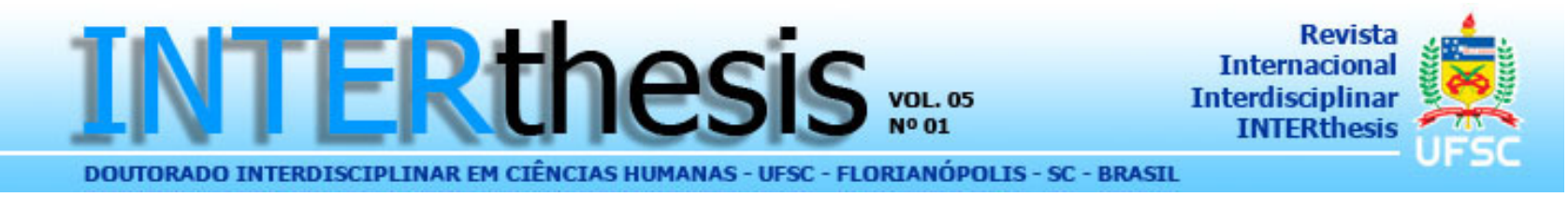

\title{
FALANDO DE MODELOS DE ASSISTÊNCIA À SAÚDE E DO PROGRAMA DE SAÚDE DA FAMÍLIA DO MINISTÉRIO DA SAÚDE - BRASIL
}

\section{ON MODELS OF HEALTH ASSISTANCE AND THE PROGRAM OF FAMILY HEALTH OF THE BRAZILIAN HEALTH DEPARTMENT}

\section{EL PROGRAMA DE SALUD DE LA FAMILIA DEL MINISTERIO DE LA SALUD DE BRASIL Y OTROS MODELOS DE ASSISTÊNCIA A LA SALUD.}

Cláudia Hausman Silveira ${ }^{1}$

\section{RESUMO}

O artigo faz referência aos três modelos que inspiraram a construção do Programa de Saúde da Família no Brasil (Cubano, Inglês e Canadense), observando suas diferenças e semelhanças e comparando com o caso brasileiro. Para tanto, também é construída uma linha relacional entre o Sistema Único de Saúde (SUS) e a necessidade de uma prática que permita a operacionalização de suas diretrizes e princípios organizativos. Assim, chega-se a conclusão de que o Programa de Saúde da Família no Brasil, pela sua proposta multiprofissional de trabalho em equipe interdisciplinar em consonância com o SUS pode ajudar a cumprir a lei da saúde no País.

Palavras-chave: SUS, Programa de Saúde da Família, Interdisciplinaridade, modelo assistencial, prática sanitária.

\section{ABSTRACT}

The article makes reference to the three models that have inspired the construction of the Program of Family Health in Brazil (Cuban, English and Canadian), observing their differences and similarities and comparing them with the Brazilian case. Therefore, an associative line is also constructed between the Only System of Health (SUS) and the necessity of a practice which allows the functioning of its lines of direction and organization principles. Thus, we reach the conclusion that the Program of Family Health in Brazil, for its multi professional work proposal in interdisciplinary teams, in accordance with the SUS, can help keep the law of health in the Country.

Key-words: SUS, Program of Family Health, Interdisciplinary, medical care model, sanitary practice

\section{RESUMEN}

1 Doutoranda do Programa de Pós-Graduação Interdisciplinar em Ciências Humanas (DICH) da Universidade Federal de Santa Catarina (UFSC), sanitarista, professora do Departamento de Saúde Comunitária da Universidade Federal do Paraná (UFPR), Mestre em Sociologia das Organizações (UFPR).

R. Inter. Interdisc. INTERthesis, Florianópolis, v.5, p. 78-103, jan./jul. 2008. 
Este artículo referencia los tres modelos que inspiraron la construcción del Programa de Salud de la Familia en el Brasil (cubano, ingles y canadiense), observando sus semejanzas y diferencias y comparando con el caso brasileño. Para tanto se construye una relación entre el Sistema Único de Salud (SUS) y la necesidad de una práctica que permita la concretización de sus principios y diretrizes. El trabajo llega a la conclusión de que el Programa de Salud de la Familia en el Brasil puede ayudar a cumplir la ley de la salud en el País proponiendo equipos multiprofesionales que desarrollen un trabajo interdisciplinario de acuerdo con el SUS.

Palabras-clave: SUS; Programa de Salud de la Familia; interdisciplinariedad; modelo asistencial; practica sanitaria

A concepção de saúde tem se transformado através dos tempos e das civilizações, fato que indica sua estreita relação com a história e a organização política, econômica e cultural de um grupo social.

A $8^{\text {a }}$ Conferência Nacional de Saúde, em 1986 no Brasil, assim definiu saúde:

Em seu sentido mais abrangente, a saúde é a resultante das condições de alimentação, habitação, educação, renda, meio ambiente, trabalho, transporte, emprego, lazer, liberdade, acesso e posse da terra e acesso a serviços de saúde. É, assim, antes de tudo, o resultado das formas de organização social da produção, as quais podem gerar grandes desigualdades nos níveis de vida. [...] A saúde não é um conceito abstrato. Define-se no contexto histórico de determinada sociedade e num dado momento de seu desenvolvimento, devendo ser conquistada pela população em suas lutas cotidianas. (ÍNTEGRA do Relatório..., 1986)

Vaitsman (1992) afirma que não se deve reduzir a determinação das doenças à determinação das formas da organização social da produção. E acrescenta:

A existência de saúde, que é física e mental, está ligada a uma série de condições
irredutíveis umas às outras. Um conceito ampliado não poderia então considerar
saúde só como resultante das formas de organização social da produção. Pois é
produzida dentro de sociedades que, além da produção, possuem certas formas
de organização da vida cotidiana, da sociabilidade, da afetividade, da
sensualidade, da subjetividade, da cultura e do lazer, das relações com o meio
ambiente. É antes resultante do conjunto da experiência social, individualizado em
cada sentir e vivenciado num corpo que é também, não esqueçamos, biológico.
(VAITSMAN, 1992, p.170)

Segundo o autor, "uma concepção de saúde não reducionista deveria recuperar o significado do indivíduo em sua singularidade e subjetividade na relação com os outros e com o mundo" (p.171).

R. Inter. Interdisc. INTERthesis, Florianópolis, v.5, p. 78-103, jan./jul. 2008. 
Em função da concepção de saúde e de sua determinação os serviços são organizados, constituindo, por sua vez, modelos assistenciais de saúde.

Segundo Campos (1989), a noção de Modelo Assistencial tem sido entendida de forma rígida e condicionadora de um desenho organizacional e técnico. Afirma que:

[ ] deveria ser conceituado como o modo como são produzidas ações de saúde e a maneira como os serviços de saúde e o Estado se organizam para produzi-las e distribuí-las. Este novo conceito tem duas utilidades imediatas: uma analítica, na medida em que permite identificar um determinado modo de produção existente; e outra operacional, que possibilita a construção de novas políticas para além da anunciação de diretrizes gerais, ou seja, permite pensar modelos assistenciais novos, imaginados enquanto objetivos estratégicos a serem atingidos. (CAMPOS, 1989, p.53)

Para o mesmo autor, historicamente, no Brasil, identificam-se vários modelos assistenciais que foram construídos através das diferentes políticas de saúde implementadas. Destaca três deles, por serem significativos na conformação do setor e por estarem ainda presentes no cenário político: o modelo liberal-privativista, o modelo racionalizador-reformista e o Sistema Único de Saúde.

O primeiro é organizado pelo mercado. Investe-se onde há possibilidade de lucro e o usuário paga sempre pela assistência, seja de forma direta ou através da Previdência Social. Isso gerou desigualdade no acesso aos serviços e estruturou duas formas de atenção: um atendimento especializado, tecnificado e resolutivo para a população de maior poder aquisitivo, e um Pronto-Atendimento, impessoal e pouco resolutivo, comprado pelo Estado, que contratava ou credenciava hospitais e serviços. Foi justamente essa intervenção estatal, no sentido do aumento de cobertura, que permitiu a expansão do modelo liberal-privativista cuja lógica de atenção médica era individual, curativa e economicamente racionalizadora. Neste modelo coube ao Estado o financiamento, a compra de serviços e o atendimento daqueles cidadãos que não faziam parte do mercado formal.

Assim, desenvolveram-se no Brasil as Campanhas Sanitárias e os Centros de Saúde tradicionais que trabalhavam apenas com alguns programas considerados necessários ao controle de endemias ou da mortalidade infantil e materna. Foi com essa lógica que, mais recentemente, se desenvolveram os "Postinhos de Saúde", dentro da proposta de atenção comunitária aos carentes e marginalizados. (CAMPOS, 1989 p.54-55)

R. Inter. Interdisc. INTERthesis, Florianópolis, v.5, p. 78-103, jan./jul. 2008. 
Esse modelo encontra-se em crise financeira, crise de eficácia e de legitimidade há pelo menos vinte anos, porém ainda conta com o apoio de alguns setores da sociedade, empresários, parte dos médicos e da população de maior poder aquisitivo.

Em função da crise do modelo anterior e da pouca expressividade dos movimentos sociais, nasce, dentro do Estado, um projeto que, sem pretender acabar com a medicina de mercado, tenta minimizar algumas distorções da sua prática liberal. Assim surge o modelo racionalizador-reformista, cujos projetos mais significativos foram, entre outros, as Ações Integradas de Saúde (AIS) e o Sistema Unificado e Descentralizado de Saúde (SUDS).

Esses projetos contribuíram para ampliar a capacidade de atenção do Estado e introduzir o planejamento de caráter racionalizador e normativo em saúde como substituto do mercado na alocação de recursos, constituindo-se em um contraprojeto aos serviços prestados e organizados pela lógica liberal. Esta coexistência dos opositores acaba por estagnar o avanço de ambos.

Assim, vem ocorrendo no Brasil uma penetração dos princípios e da organização liberal mesmo na parte "reformada" dos serviços; fazendo com que antigos Centros de Saúde transformem-se em Pronto-Atendimento, Hospitais Municipais sejam organizados como se fossem privados, recursos públicos continuem passando ao setor privado para financiar uma assistência ainda gerenciada pela busca do lucro. Particularmente, interessa a essa discussão assinalar que dentro desse modelo híbrido a "rede básica" não tem conseguido desenvolver-se, a não ser como extensão dos pronto-atendimentos do setor privado, principalmente porque os recursos prioritariamente continuam sendo investidos com outras finalidades. (CAMPOS, 1989 p.55-56)

O terceiro modelo, um projeto em construção, é o Sistema Único de Saúde (SUS), no qual o planejamento substitui o mercado de modo a permitir que as necessidades de saúde sejam o critério de maior importância na organização da atenção. Exige uma rede básica bastante grande para garantir, inclusive com pronto-socorro, a entrada no sistema. Possui, segundo Campos (1989, p.56), alguns "objetivos estratégicos":

a) constituir uma rede básica distribuída por critérios demográficos e socioeconômicos;

b) compatibilizar as práticas preventivas, individuais e coletivas com a atenção à demanda espontânea;

R. Inter. Interdisc. INTERthesis, Florianópolis, v.5, p. 78-103, jan./jul. 2008. 
c) dispor de tecnologia, trabalhadores capacitados, apoio diagnóstico e terapêutico e infra-estrutura física capaz de possibilitar uma resolutividade de, aproximadamente, $80 \%$ dos problemas;

d) dispor de postos na rede básica que ofereçam o maior número de atividades possível todos os dias, em diversos períodos, fazendo com que o usuário se desloque o mínimo possível da sua região;

e) humanizar o atendimento e formar um vínculo com o usuário que seja baseado na parceria e no respeito às diferenças;

f) construir um sistema de gerência capaz de democratizar os processos de decisão e controle com competência técnica e política.

O alcance desses "objetivos estratégicos", necessários à construção do modelo, que apresenta as diretrizes e princípios organizacionais descritos no capítulo 2 (item 2.1) do presente trabalho, faz com que o SUS percorra uma trajetória conflituosa em meio às suas próprias contradições e àquelas oriundas da coexistência de outros modelos.

Ao se pensar na concepção de saúde como norteadora da organização dos serviços, Vaitsman, ao construir um conceito ampliado, confere sentido às práticas sanitárias construídas para atender tanto à lógica curativa individual quanto à lógica preventiva e coletiva. Este conceito resgata o usuário e os profissionais como sujeitos da produção em saúde e explicita uma relação intrínseca entre a determinação estrutural e individual do processo saúde/doença.

$\mathrm{Na}$ busca da operacionalização do modelo, através da construção dos distritos sanitários, alguns municípios têm buscado referenciar-se na experiência de países cujos sistemas de saúde são reconhecidos mundialmente. Os três modelos estrangeiros que mais têm inspirado as experiências nacionais são o cubano, o canadense e o inglês.

Segundo Dupuy (1991), para o modelo de Cuba a questão da saúde não é somente um problema teórico, é também um problema prático e intersetorial que precisa ser enfrentado pela saúde pública. A categoria saúde-doença, base da medicina, é social e histórica e sofre mudanças em função dos modos de produção econômico-sociais e das bases de justiça social e eqüidade que fundamentam a organização de determinado grupo social. Por isso, a saúde e as instituições responsáveis por ela não podem ser concebidas como autônomas ou independentes da sociedade à qual pertencem e que as

R. Inter. Interdisc. INTERthesis, Florianópolis, v.5, p. 78-103, jan./jul. 2008. 
produziu. Em Cuba, a responsabilidade pela saúde da população é do Ministério de Saúde Pública, único dirigente do governo social (DUPUY, 1991 p.4-5).

As principais medidas adotadas pelo Ministério da Saúde de Cuba no período de trinta anos de revolução são as seguintes:

a) decisão política do Estado e do governo para realizar transformações profundas em saúde;

b) reconhecimento da saúde como um direito do povo e um dever e responsabilidade do Estado;

c) garantia da saúde a cada cidadão, pelo Estado, tornando gratuita a atenção à saúde para grupos, famílias e indivíduos;

d) criação de um único órgão de saúde - o Ministério de Saúde Pública -, com a responsabilidade principal de garantir a saúde de toda a população;

e) a medicina tem uma base profundamente profilática, curativa, integral, sociobiológica e não exclusivamente biologicista;

f) aumento substancial do orçamento para a Saúde Pública, visando atender às necessidades crescentes da medicina hospitalar e ambulatorial;

g) garantia da atenção à saúde através da Medicina Familiar: há uma policlínica e um consultório do Médico de Família para cada 720 indivíduos, atendendo toda a população urbana e rural;

h) participação das massas na solução dos problemas de saúde da nação por meio das diferentes instâncias do Poder Popular e organizações de massas;

i) desenvolvimento, em todos os níveis de Saúde Pública, de um processo de integração da assistência, docência e investigação.

Segundo Dupuy, Cuba, um país subdesenvolvido, desde 1983 havia conseguido cumprir o objetivo emblemático estabelecido na Conferência de Alma Ata em 1978 de “Saúde Para Todos no ano 2000". Isto, no entanto, não quer dizer que o projeto de Estado não tenha sofrido ajustes e, em 1985, é introduzida a figura do Médico de Família, figura chave para o sistema até hoje.

O modelo do médico de família de Niterói é de inspiração cubana.

R. Inter. Interdisc. INTERthesis, Florianópolis, v.5, p. 78-103, jan./jul. 2008. 
Vasconcellos (1998, p.167), cita o encarte de divulgação do Programa do Médico de Família de Niterói que cita o modelo cubano:

O Plano Médico de Família de Cuba fundamenta-se na concepção humanística, a qual prioriza o homem como sujeito de sua história, a partir de determinantes sociais. Em termos de programação, o conceito de medicina familiar não estabelece uma relação de subordinação entre partes ou níveis, e sim uma matriz de inter-relações de apoio e fortalecimento, o que não é confundido com a quebra de hierarquização dos níveis de atenção.

Para a autora, o Programa Médico de Família de Niterói foi criado como uma estrutura paralela à chamada "rede" para viabilizar seu projeto político. A equipe básica era formada pelo médico generalista e a auxiliar de enfermagem, tendo por retaguarda supervisores nas mais diferentes áreas.

O modelo canadense se aproxima do Movimento de Cidades Saudáveis da Organização Mundial de Saúde, no qual verifica-se a ênfase da saúde como política central de governo e a articulação intersetorial como principal estratégia de atuação. (SILVA JUNIOR,1998, p.94)

No Fórum "Saúdecidade", realizado em Curitiba em dezembro de 1994, o Dr. Jack Lee, Chefe do Departamento de Saúde Pública de Toronto, afirmou que os principais pontos a serem trabalhados de forma indissociável no projeto das cidades saudáveis são a eqüidade, a economia e o desenvolvimento. O Estado tem a função de prover políticas e legislação ambiental e educacional, bem como de estabelecer parcerias com a comunidade que lhe garantam exprimir suas necessidades e buscar soluções. Para Lee, Toronto pretende uma política de saúde baseada na participação da comunidade, cooperação multissetorial e horizontal, pois uma cidade saudável é aquela que está, continuamente, modificando e recriando mecanismos sociais que permitam mudanças não só nos indicadores de saúde, mas também nos processos desenvolvidos para a sua produção. Neste enfoque, a atuação do setor saúde deve dar ênfase à prevenção, a tomada de decisão deve ser compartilhada entre todos os segmentos da comunidade e governo e, ainda, deve haver co-responsabilidade na construção e desenvolvimento dos processos geradores de saúde.

O médico de família do modelo canadense é responsável pela saúde das famílias a ele vinculadas, independentemente dos seus locais de residência, e utiliza o método R. Inter. Interdisc. INTERthesis, Florianópolis, v.5, p. 78-103, jan./jul. 2008. 
clínico centrado no paciente, chamado de diagnóstico abrangente. Este tipo de atenção exige seis intercomponentes: a exploração da doença e da experiência de adoecer, a compreensão integral do indivíduo, a busca de um campo comum, a incorporação da prevenção e promoção da saúde, a melhora da relação médico-paciente e a percepção realista das situações. Para o Canadian College of Family Physician, o médico de família incorpora em sua prática quatro princípios de Medicina Familiar: competência clínica, prática que leva em conta a idéia de "população de risco", respeito pela comunidade e suas características e vínculo estreito com seus pacientes. Tal figura de médico, com aprofundada formação clínica, tem sido o ideal das especializações em medicina familiar, reivindicado por esta categoria profissional.

O modelo inglês constrói-se, historicamente, na segunda metade do século XIX, quando o Estado liberal não consegue mais furtar-se das investigações sobre as condições de vida nas cidades, das ações de saneamento do meio, do controle das endemias e da assistência médica aos pobres no âmbito local.

Segundo Rosen (1994), as "Leis dos Pobres" na Inglaterra constituíram-se em um sistema de assistência que surge no século XVI e subsiste até a Segunda Guerra Mundial, tendo sido alvo de diversas mudanças nesse longo período. Por volta de 1600 a pobreza e o desemprego já assumiam proporções alarmantes na Inglaterra isabelina, fazendo com que o Estado assumisse o problema que a Igreja não conseguia mais resolver. As freguesias foram orientadas a arrecadar impostos, conseguir empregos, punir os indolentes e prestar caridade aos idosos, doentes e incapacitados.

No século XVIII, os trabalhadores que recebiam salário abaixo da subsistência passaram a receber pensões que, por sua, vez oneraram de tal forma os gastos do Estado que levaram à votação, em 1834, de uma nova Lei dos Pobres, bem mais dura, em que a pobreza dos fisicamente capazes era entendida como uma falha moral e a assistência passa a ser restrita às casas asilares (workhouses). O crescimento de filosofias humanitárias no século XIX leva ao abrandamento da nova lei.

É preciso entender que é a partir da Lei dos Pobres que a medicina inglesa tornase social, impondo um controle médico sobre o pobre. Um elo de autoritarismo une ricos e pobres nas cidades, os primeiros garantindo não serem afetados pelas epidemias originadas nas classes pobres e os segundos podendo se tratar gratuitamente ou com baixo custo. Esta forma de atenção torna as classes pobres mais aptas ao trabalho e R. Inter. Interdisc. INTERthesis, Florianópolis, v.5, p. 78-103, jan./jul. 2008. 
menos perigosas às classes ricas. Em 1875, a criação do health service, com seus aproximadamente mil health officers, garante coletivamente o mesmo controle já mantido pela Lei dos Pobres. Este serviço tinha por funções localizar e intervir nos locais insalubres, controlar e obrigar à vacinação e localizar e registrar a ocorrência de doenças epidêmicas. Tal forma autoritária de controle médico não se desenvolve impunemente e é enfrentada, historicamente, por diversos grupos, principalmente de dissidência religiosa. (Foucault, 1998)

A atribulada primeira metade do século $X X$ (que passa por duas guerras mundiais, a Revolução Russa e a crise capitalista dos anos 30) acaba por reforçar a intervenção do Estado na economia que, pressionado pelas organizações de trabalhadores, precisa desenvolver políticas sociais que terminam por gestar o seu Sistema Nacional de Saúde. A legislação social inglesa substitui as Leis dos Pobres por um abrangente sistema de serviços públicos. O desemprego industrial do século $\mathrm{XX}$ mostrou também as determinações estruturais da pobreza.

A medicina social inglesa permitiu a coexistência de três sistemas de atenção à saúde em um mesmo grupo social: uma medicina assistencial dirigida aos mais pobres, uma medicina coletiva encarregada de atuar sobre situações de risco coletivo (vacinas, epidemias, etc.) e uma medicina privada cujo benefício restringe-se à população que dispõe de meios para comprá-la. Este modelo tem inspirado a organização de diversos sistemas nacionais de saúde, inclusive o brasileiro.

Em 1920, um médico inglês chamado Bertrand Dawson critica o modelo americano sistematizado por Flexner e propõe a reestruturação dos serviços de saúde na Inglaterra. Tinha o Estado como provedor e gerenciador de políticas de saúde executadas por serviços responsáveis por ações curativas e preventivas em regiões geograficamente determinadas. Também falava em ações coordenadas realizadas por médicos generalistas que atuassem sobre indivíduos e comunidades.

Os serviços para as famílias de uma região específica devem possuir como base um centro primário de saúde, ou seja, um estabelecimento que ofereça os serviços de medicina curativa e preventiva e que esteja a cargo de médicos generalistas, junto com um serviço de enfermagem eficiente, e que tenha a colaboração de consultores e especialistas visitantes. Os centros de saúde serão de diferentes tamanhos e níveis de complexidade, de acordo com as condições locais ou quanto à sua localização na cidade ou áreas rurais. O pessoal consiste, na sua maioria, de médicos do distrito correspondente, sendo possivel assim para os pacientes

R. Inter. Interdisc. INTERthesis, Florianópolis, v.5, p. 78-103, jan./jul. 2008. 
seguir com seus próprios médicos. Um grupo de centros primários de saúde deve, por sua vez, ter um centro secundário de saúde como base. [...] Os centros de saúde secundários, por sua vez, devem formar vínculo com o hospital. (DAWSON, 1920, apud SILVA JUNIOR, 1998, p.54-55)

Silva Junior (1998), salienta que a aparente polaridade da medicina flexneriana americana-tecnificada, especializada, medicalizada, hospitalocêntrica, medicocêntrica e de alto custo - com a proposta de Dawson verdadeiramente representa os dois lados de uma mesma moeda. A conjuntura política e econômica inglesa da época fez com que o Estado incorporasse as demandas dos trabalhadores sem que fosse alterada a estrutura de dominação de classe e a hierarquia de poder. Esta política atenuou as vocações socialistas do Partido Trabalhista inglês na década de 40. A proposta de Dawson foi implantada nessa mesma década com o plano Beveridge.

Assim, os médicos generalistas, com menor prestígio profissional, passaram a atender às periferias urbanas e às classes trabalhadoras, sendo cooptados pelo Sistema de Saúde, que os utilizava como triadores para os hospitais e médicos especialistas. Ainda hoje, a indústria médico-farmacêutica influencia a tendência dos gastos em saúde quando fixa os preços dos produtos comprados pelo Estado inglês.

Em 1994, o Dr. Walter W. Rosser, professor do Departamento de Família e Medicina Comunitária da Universidade de Toronto, proferiu palestra em Curitiba fazendo uma comparação entre países que trabalham com cuidados primários de saúde. Ele afirma que as práticas generalistas, ainda hoje, têm um papel muito importante no sistema nacional de saúde britânico. Mais da metade dos médicos na Grã-Bretanha são médicos gerais comunitários (general partitioners - GPs). Todo cidadão britânico deve se registrar com um GP, que é sua porta de entrada para o sistema. Um especialista só atenderá um paciente se ele for referenciado por um médico geral comunitário. Os GPs são pagos por um sistema de captação e são encorajados a trabalhar junto com uma enfermeira comunitária, fisioterapeutas e outros profissionais da saúde. A partir de 1990 o médico geral comunitário que tem mais de 7.000 pacientes cadastrados deve manter um contrato com hospitais e especialistas para garantir a atenção em todos os níveis. Isto força os hospitais a melhorar a qualidade da atenção e, acredita-se, a baixar o custo do atendimento. O sistema britânico tem estimulado os GPs a desenvolverem clínicas e, com a ajuda de outros profissionais, ofertarem algumas práticas específicas, além de fazerem visitas domiciliares na comunidade.

R. Inter. Interdisc. INTERthesis, Florianópolis, v.5, p. 78-103, jan./jul. 2008. 
O modelo inglês é mundialmente reconhecido pela sua resolutividade e tem sido usado como referência para diversas experiências, inclusive na Ásia e África de influência inglesa. No Brasil, em Porto Alegre, no Rio Grande do Sul, o Grupo Hospitalar Conceição (GHC) é um dos maiores complexos hospitalares da América Latina, formado por quatro sociedades anônimas: o Hospital Nossa Senhora da Conceição S.A., o Hospital da Criança Conceição S.A., o Hospital Cristo Redentor S.A. e o Hospital Fêmina S.A., cada um com CGC próprio. O Ministério da Saúde tem $98 \%$ das ações do grupo e financia sua folha de pessoal. O custeio se dá através do faturamento.

Em 1983 começa o Serviço de Medicina de Família (SMF), com uma unidade experimental que visava formar Médicos Gerais Comunitários (MGC) e prestar assistência à comunidade vizinha ao hospital. Posteriormente, a atenção é ampliada para a comunidade funcional do Grupo Hospitalar Conceição. A população da zona norte de Porto Alegre já procurava o Hospital Conceição, que tinha autonomia legal para investir na proposta. O serviço começou com quatro unidades básicas de saúde, chegando a treze no período de 1990 a 1994. O espaço físico necessário foi viabilizado pela população local, que se responsabilizou pela delimitação e manutenção da área de abrangência do serviço. Em 1994, na gestão do então prefeito Tarso Genro (PT), a Secretaria Municipal da Saúde de Porto Alegre assume o processo de municipalização da saúde e define priorizar outras áreas para expandir a rede. Esta municipalização tardia é fruto de conflitos político-partidários entre o governo do Estado do Rio Grande do Sul (PMDB) e as duas gestões do PT na capital. A Secretaria Municipal negava-se a receber uma rede sucateada herdada do processo de estadualização da saúde e tampouco possuía serviço próprio, exceção feita ao Pronto-Socorro Municipal, um serviço de referência para o País.

Hoje, a Secretaria da Saúde de Porto Alegre conta com 30 postos de saúde que fazem Saúde da Família e que foram estruturados com a assessoria do Grupo Hospitalar Conceição, além dos 13 postos gerenciados por esse hospital. Além disso, oferece aproximadamente outros 100 postos de serviços de atenção primária.

A residência médica tem a duração de dois anos, sendo o primeiro ano desenvolvido integralmente dentro de unidades básicas de saúde e o segundo dividido igualmente entre a unidade básica e o hospital. O serviço baseou-se no modelo inglês de assistência e, também, teoricamente, nos anais da Conferência de Alma Ata, ocorrida na R. Inter. Interdisc. INTERthesis, Florianópolis, v.5, p. 78-103, jan./jul. 2008. 
Rússia em 1978. Sua proposta de trabalho conseguiu se legitimar dentro de uma instituição hospitalar apoiando-se em movimentos populares e em alianças políticas na busca da construção do SUS. Como foi uma das primeiras propostas institucionalizadas a apresentar resultados concretos e satisfatórios, passou a ser referência visitada por gestores e equipes que tinham a responsabilidade de construir sistemas locais de saúde.(Ferreira et alli, 1996)

Para o Chefe da Divisão de Saúde Comunitária do Hospital Nossa Senhora da Conceição, Djalmo Sanzi Souza, entrevistado em setembro de 1999, a idéia dos cuidados primários em saúde precisa ser resgatada e entendida de forma complementar a um sistema que apresente referência e contra-referência em diferentes níveis de complexidade da atenção.

O que chama a atenção na abordagem dos três modelos é que, em fases mais atuais de seu desenvolvimento na década de 80, assumem como marco conceitual as recomendações da Conferência de Alma Ata, que referenda os cuidados primários de saúde e a racionalização de recursos como estratégias para alcançar o objetivo de saúde para todos no ano 2000. Um segundo ponto é que os três modelos citados são medicocêntricos, ou seja, tem neste profissional o pilar do sistema.

Já no caso brasileiro, na sua história mais recente, a equipe de saúde e o compartilhamento de responsabilidades pelos seus membros têm sido fundamentais na oferta dos serviços. Segundo Nemes (1990, p.76), a programação foi a forma de organização que a Saúde Pública, a partir da experiência de São Paulo, encontrou no Brasil para responder às necessidades das políticas de extensão de cobertura dos serviços de saúde na década de 70 , e fundamenta-se em duas vertentes de pensamento sobre os serviços de saúde: a medicina comunitária e o planejamento em saúde.

A medicina comunitária surge como um modelo alternativo para realizar uma reforma médica nos EUA dos anos 60 que visava atender às minorias marginalizadas, buscando intervir também na organização dos serviços.

A medicina comunitária é uma resposta à inadequação da prática médica para atender às necessidades de saúde das populações que devem ser solucionadas tanto como resposta ao princípio do direito à saúde como por sua significação para o processo de desenvolvimento social. Mas localiza os elementos responsáveis pela inadequação não apenas nos aspectos internos do ato médico individual, mas sobretudo em aspectos organizacionais da estrutura da atenção que tomem

R. Inter. Interdisc. INTERthesis, Florianópolis, v.5, p. 78-103, jan./jul. 2008. 
por base o cuidado dos grupos sociais, antes que dos indivíduos. (DONNANGELO, 1976, p.86)

A medicina comunitária consolida-se como movimento mundial na Conferência Internacional sobre Cuidados Primários de Saúde de Alma Ata. A programação em saúde incorpora a atenção primária à saúde integrando atividades de promoção, prevenção e cura em uma mesma unidade, regionalizando e hierarquizando as atividades e utilizando amplamente trabalhadores não médicos nos serviços.

O Planejamento normativo, metodologia de governo no período da ditadura no Brasil, estende suas propostas economicistas aos setores sociais. Segundo Nemes, "programar é sinônimo de planejar o melhor uso para os recursos disponíveis". (1990, p.77). Assim, as idéias da medicina comunitária ajudariam a usar de modo mais racional os recursos disponíveis, apoiada nas concepções do modelo Cendes/OPS (1965) de planejamento e programação em saúde. Ainda para a autora, "a programação procurou incorporar a assistência médica individual a um conjunto de outras atividades que compunham um plano de intervenção dirigido a coletivos". (p.78)

$O$ enfoque programático definia atividades de rotina e atividades eventuais. As primeiras eram previstas por grupos de clientes que participavam de programas e subprogramas. Suas principais atividades normatizadas eram o atendimento médico individual e as atividades básicas realizadas pelo restante da equipe, como vacinação, visita domiciliar, chamada aos faltosos e realização dos exames laboratoriais disponíveis. As atividades eventuais destinavam-se ao atendimento da demanda espontânea individual.

Os dois conjuntos de atividades foram articulados pela História Natural da Doença de Leavell e Clark, em 1976. Os programas respondiam a grupos populacionais específicos por idade, sexo, etc. e, os subprogramas, aos danos sofridos por aqueles grupos, tudo isso visando aumentar a eficácia dos serviços. Dentro da mesma lógica, para estender a cobertura são instituídas a pré e a pós-consulta, bem como o atendimento de enfermagem, buscando racionalizar a utilização da consulta médica. Além disso, trabalhava-se com o conceito de assistência integral, afastando da Saúde Pública a idéia de fazer somente prevenção. O enfoque programático introduz um forte controle no sistema, normatiza os processos de trabalho e sistematiza a avaliação.

O enfoque de risco, que fundamenta o Programa de Saúde da Família R. Inter. Interdisc. INTERthesis, Florianópolis, v.5, p. 78-103, jan./jul. 2008. 
conceitualmente, é uma das correntes de explicação multicausal na determinação do processo saúde/doença. Este modelo embasou também a construção do enfoque programático na operacionalização da Saúde Pública ainda na década de 70.

Porém, tanto a Medicina Comunitária quanto a Conferência de Alma Ata perdem potência racionalizadora, uma vez que não conseguem mudar a lógica do procedimento centrado no profissional médico, e tampouco propõem alterar a micropolítica do processo de trabalho médico cotidiano.

Neste sentido, o Programa de Saúde da Família (PSF) - ou Estratégia de Saúde da Família (ESF) - do Ministério da Saúde no Brasil busca a construção de uma prática sanitária multiprofissional e interdisciplinar que busca superar as limitações acima.

Para tanto, é preciso entender a construção da Estratégia do ponto de vista da necessidade de sua criação e conexão com o Sistema Único de Saúde (SUS).

As diretrizes do SUS devem ser compreendidas da seguinte forma:

- Universalidade: é a garantia da atenção à saúde a todo e qualquer cidadão nos serviços públicos ou contratados no território nacional, em consonância com a passagem da Constituição Brasileira segundo a qual "a saúde é direito de todos e dever do Estado...”. (BRASIL, Constituição..., 1988, p.91) Não é sinônimo de gratuidade.

- Eqüidade: todo cidadão é igual perante o SUS e será atendido, conforme suas necessidades, até o limite do sistema. Não é sinônimo de igualdade.

- Integralidade: o homem é um ser integral, possuindo, minimamente, três dimensões: uma biológica, uma emocional e uma social, a serem contempladas por um sistema de saúde também integral, voltado a promover, proteger e recuperar sua saúde em todos os níveis de complexidade.

Seus princípios organizativos orientam para a:

- Regionalização e hierarquização: os serviços são organizados em níveis de complexidade tecnológica crescente, dispostos em uma área geográfica delimitada e com definição da população a ser atendida com vistas a um aumento da eficácia, eficácia e efetividade do sistema.

- O acesso deve dar-se pelo nível primário de atenção, a unidade básica de saúde, que deve resolver a maioria dos problemas e referenciar à serviços de maior complexidade, se necessário. Organizado desta forma,

R. Inter. Interdisc. INTERthesis, Florianópolis, v.5, p. 78-103, jan./jul. 2008. 
favorece as ações de vigilância, educação, atenção ambulatorial e hospitalar.

- Resolutividade: trata-se de dar solução aos problemas dentro de cada nível de competência.

- Descentralização: redistribuição das responsabilidades quanto às ações e serviços de saúde entre os vários níveis de governo, a partir da idéia de que quanto mais localmente a decisão for tomada, maior a chance de eficácia e efetividade.

- Deverá haver uma profunda redefinição das atribuições dos vários níveis de governo com um nítido reforço do poder municipal sobre a saúde municipalização da saúde -, cabendo ao município, portanto, a maior responsabilidade das ações.

- Participação dos cidadãos: garantia constitucional de participação organizada no processo de formulação de políticas e no controle de sua execução em todos os níveis, através de: Conselhos Locais, Municipais, Estaduais e Nacional de Saúde e da organização de Conferências Municipais, Estaduais e Nacional de Saúde; garantidas todas as informações necessárias à população no que diz respeito à saúde.

- Complementaridade do setor privado: quando for necessária a contratação de serviços, exigem-se três condições (BRASIL, Constituição..., 1988):

- deve se dar na forma de um contrato de direito público;

- o serviço privado deve incorporar os fundamentos, princípios e técnicas do SUS, uma vez que atua em nome deste;

- deverá obedecer à mesma lógica organizativa do SUS, atendendo a sua necessidade de regionalização e hierarquização.

Terão prioridade os serviços não lucrativos (BRASIL, Constituição..., 1988). Primeiramente, o gestor deve planejar o setor público e depois complementá-lo com o privado, seguindo as diretrizes e princípios do SUS. É fundamental definir normas e procedimentos a serem anexados aos convênios e contratos.

A partir desse momento histórico, diversos atores sociais que participaram do movimento sanitário brasileiro passaram a se incorporar ao aparelho de Estado na condução do processo de construção do SUS.

R. Inter. Interdisc. INTERthesis, Florianópolis, v.5, p. 78-103, jan./jul. 2008. 
Contudo, a incompatibilidade ideológica entre o projeto da reforma sanitária brasileira e a organização política e econômica da sociedade brasileira determina um ritmo de desenvolvimento muito lento na implementação do projeto.

Por maior que seja o arcabouço jurídico e legal que ampare o SUS, é no "fazer-se cotidiano" que ele adquire forma e consistência. Eugênio Vilaça Mendes chama de espaço operativo "aquele em que um sistema de saúde adquire concretude mediante o estabelecimento, num território determinado, de uma relação direta e recíproca entre suas unidades produtoras de serviços, geridas por uma autoridade sanitária e uma população dada, com suas necessidades e representações" (1995, p.139). Ele aponta como o espaço operativo do SUS o distrito sanitário, criado pelo Art. 10 da Lei $\mathrm{n}^{\circ} 8080$, entendido como "o processo social de mudanças das práticas sanitárias no Sistema Único de Saúde" (1995, p.159), não se restringindo a ser apenas mais uma etapa no processo de descentralização político-administrativa do sistema de saúde.

O processo de distritalização, tal como nos aponta Mendes (1995), apóia-se em três conceitos fundamentais: território, problema e práticas sanitárias, discutidos a seguir:

Território - a idéia de distrito sanitário está associada a uma base territorial que, em função do modelo adotado na organização dos serviços para resolver problemas de saúde, deve adotar uma concepção dialética de território, o território-processo. Para Giacomini,

\footnotetext{
Nesta concepção o espaço social é organizado conforme uma construção dinâmica, que leva em conta as tensões e os conflitos sociais existentes [...] que apontam para a construção de critérios que levam em conta a cultura, a participação política da sociedade organizada, o perfil epidemiológico da saúde/doença, a realidade sócio-econômica que divide a sociedade em classes e frações, diferentes umas das outras em seus modos de viver, adoecer e morrer. (GIACOMINI,1992, p.60)
}

O autor inclui na construção dos critérios os equipamentos disponíveis nos serviços de saúde, além de aspectos demográficos, geográficos e divisões administrativas preexistentes. Ele alerta para a complexidade da construção do território-processo que se realiza por "aproximações sucessivas" e, portanto, nunca está concluído.

A construção do território-processo identifica diferentes conjuntos sociais no seu interior que demandam sua identificação, através de uma diagramação dinâmica que associa os problemas às condições de vida dos diferentes grupos populacionais, 
configurando-se nos chamados "mapas inteligentes".

Mendes (1995) sugere a seguinte subdivisão para o território do distrito sanitário: Território-Distrito, que obedece à lógica político-administrativa; Território-Área, que se refere à área de abrangência de uma unidade de saúde, um espaço de organização básico da prática da atenção à demanda; e Território-Microárea, como espaço definido pela homogeneidade socioeconômico-sanitária, que se aproxima do conceito de "área homogênea de condições de vida" e que tem como objeto a prática da vigilância à saúde.

Dentro da área homogênea de condições de vida pode-se identificar uma (ou mais de uma) "micro-área de risco", que é um espaço privilegiado de "enfrentamento dos problemas de saúde, de forma contínua, através de operações direcionadas à superação dos nós críticos identificados na rede causal”. (Mendes, 1995, p.168). As micro-áreas de risco são sempre o espaço prioritário das ações.

Problema - segundo Matus (1987a), o problema traduz aquela diferença entre o "é" e o "deve ser". Por isso diz também que ele é sempre "auto-referenciado", pois ele será problema dependendo do ator social que explica a realidade. Portanto, a concepção de saúde é fundamental para a problematização nesta área. Outra questão fundamental é o conhecimento do território nas suas singularidades.

A principal diferença entre o enfoque por problema e o enfoque por programa é que este último, da forma como tem sido desenvolvido, tem servido às concepções tecnoburocráticas dos serviços de saúde sem respeitar as necessidades de saúde da população, nem tampouco as singularidades dos territórios-processo envolvidos no planejamento local. O enfoque por programa parte sempre de problemas definidos e explicados da mesma forma para todos, segmentando a realidade, que deve ser pensada de forma multidisciplinar. Citando Mendes, pode-se dizer que seguidamente encontra-se a seguinte situação: "enquanto a sociedade tem problemas, as organizações de saúde têm programas, [...] que não dão conta de responder aos desafios de uma realidade articulada por problemas complexos e mal-estruturados, necessitando para seu enfrentamento uma ação interdisciplinar" (1995, p.171).

Seguindo este raciocínio pode-se afirmar que o enfoque por problemas parte de um território, onde atores auto-referidos ideologicamente encontram e explicam problemas que serão enfrentados através de práticas sanitárias norteadas pela concepção de saúde da equipe e construídas de forma interdisciplinar.

R. Inter. Interdisc. INTERthesis, Florianópolis, v.5, p. 78-103, jan./jul. 2008. 
Cabem aqui algumas observações:

a) é importante evidenciar a diferença entre uma mera sobreposição de conhecimentos (multidisciplinaridade) e uma integração conceitual e metodológica de duas ou mais disciplinas (interdisciplinaridade), básica tanto para a eficácia do enfrentamento dos problemas quanto para o crescimento da própria equipe, e que deve estar atenta para a introdução de novos profissionais e de novos saberes, quando necessários, seja na forma de assessoria ou de forma mais permanente;

b) ainda na perspectiva acima, esta interação de conhecimentos deve articular um "campo de produção do cuidado" (MERHY E FRANCO, 1999) dentro do qual a equipe de referência do usuário elaboraria um "projeto terapêutico" sob a gerência de um profissional, o "gestor do cuidado";

c) o enfrentamento de determinados problemas pode ser realizado através de programas, quando isto for conveniente, guardando as devidas adaptações. Não precisamos e não devemos partir sempre do zero; o que se coloca é a impropriedade de nortear as nossas ações por programas preestabelecidos.

Pode-se afirmar ainda que o enfoque por problema leva a um melhor diagnóstico estratégico, uma vez que possibilita o compartilhamento, no interior de um território, dos saberes de diversos atores, além de abrir espaço à população no planejamento das ações.

Segundo Mendes (1995), os problemas podem exigir fundamentalmente duas formas de enfrentamento: uma contínua, cotidiana, que se constitui no objeto das práticas sanitárias da vigilância à saúde, cujo maior espaço de atuação é no Território-Microárea; a outra, ocasional, quando percebida e demandada pela população, através da prática da atenção à demanda. Assim, para o autor, deparamo-nos com dois tipos de problemas de saúde: os problemas de enfrentamento contínuo (PEC) e os problemas de enfrentamento ocasional (PEO).

Além dos problemas de saúde propriamente ditos, a equipe enfrenta também os problemas de organização dos serviços, que, seguidamente, constituem um entrave a ser resolvido para garantir a solução ou a intervenção nos primeiros.

Os problemas já solucionados exigem ações que mantenham, consolidem e avaliem os resultados para garantir a resolutividade do sistema.

R. Inter. Interdisc. INTERthesis, Florianópolis, v.5, p. 78-103, jan./jul. 2008. 
Práticas Sanitárias - são entendidas como "o conjunto de processos de trabalho articulados em operações - que impõem uma estratégia de ação sobre os determinantes e os condicionantes dos problemas ou sobre os efeitos da existência deles num território determinado". (MENDES, 1995, p.176)

Assim, identificam-se duas práticas sanitárias: uma delas voltada para a intervenção sobre os problemas de enfrentamento contínuo, que se fundamenta na promoção à saúde e na atenção coletiva do modelo sanitário; e outra voltada para a intervenção pontual sobre os problemas de enfrentamento ocasional, que se fundamenta na atenção à demanda no nível individual auto-percebido do modelo clínico.

Apesar de a intervenção no distrito sanitário utilizar de forma hegemônica o enfrentamento contínuo de problemas, as duas práticas devem ser organizadas de forma compatível, pois o enfrentamento de problemas ocasionais confere legitimidade ao sistema e aporta informações epidemiológicas às ações coletivas.

A vigilância à saúde deve contemplar ambas as práticas, que devem ser organizadas atendendo a lógicas próprias, sem perder de vista a integralidade das ações.

Quanto aos processos de trabalho, para Merhy e Franco (1999, p.30) os "fazeres" que enfrentam problemas se concretizam nas "tecnologias de trabalho" utilizadas para produzir saúde. No mesmo trabalho, definem tecnologia como "o conjunto de conhecimento e agires aplicados à produção de algo". Desta forma, entendem que o acolhimento (universalização do acesso, escuta qualificada do usuário e compromisso com a resolução do problema), o vínculo/responsabilização (estabelecimento de referência entre equipe e usuário e responsabilidade quanto à produção do cuidado) e a autonomização (produção de cuidado que leva à autonomia do usuário) são tecnologias fundamentais para a formação de uma nova subjetividade entre os profissionais de saúde.

Nessa perspectiva, a Estratégia de Saúde da Família se coloca como a Prática Sanitária proposta pelo Ministério da Saúde capaz de contribuir para a reorientação do modelo assistencial a partir da rede básica de atenção à saúde de acordo com os princípios do SUS, conferindo às Unidades Básicas de Saúde uma nova forma de atuação, com definição de responsabilidades entre serviço e população.

Os objetivos específicos do PSF são:

\footnotetext{
- Prestar, na unidade de Saúde e no domicílio, assistência integral, contínua, com resolubilidade e boa qualidade às necessidades de saúde da população adscrita. - Intervir sobre os fatores de risco aos quais a população está exposta.
}

R. Inter. Interdisc. INTERthesis, Florianópolis, v.5, p. 78-103, jan./jul. 2008. 
- Eleger a família e o seu espaço social como núcleo básico de abordagem no atendimento à saúde.

- Humanizar as práticas de saúde através do estabelecimento de um vínculo entre os profissionais de saúde e a população.

- Proporcionar o estabelecimento de parcerias através do desenvolvimento de ações intersetoriais.

- Contribuir para a democratização do conhecimento do processo saúde/doença, da organização dos serviços e da produção social da saúde.

- Fazer com que a saúde seja reconhecida como um direito de cidadania e, portanto, expressão da qualidade de vida.

- Estimular a organização da comunidade para o efetivo exercício do controle social. (BRASIL, Ministério..., 1997, p.10).

Ainda segundo o Ministério da Saúde (BRASIL, Ministério..., 1997, p.1-33), devem ser seguidas as diretrizes abaixo, respeitando as diferenças loco-regionais:

- Caráter substitutivo das práticas convencionais, individuais e curativas, centradas na figura do médico. Embora seja hierarquizado, apresenta caráter complementar ao sistema que tem como porta de entrada a unidade básica de saúde.

- Adscrição da clientela, o que exige definição de território e área de abrangência a serem estabelecidos localmente, tomando-se em conta critérios de ordem sociopolítica e econômica das regiões, bem como densidade demográfica, acesso aos serviços e outros critérios de relevância local.

- Cadastramento, ou seja, criação de um sistema de informação, construído localmente através de visitas domiciliares que ajudarão a formar um vínculo entre equipe de saúde e população e um diagnóstico que permitirá identificar, além dos problemas de saúde, outras demandas que contribuirão para a melhoria da qualidade de vida da comunidade.

- A instalação das unidades de Saúde da Família poderá acontecer em unidades já existentes ou construídas para tal fim, desde que adequadas ao número de profissionais que irão compor a equipe, obedecendo aos princípios básicos de capacidade instalada, dimensão da população a ser atendida, enfrentamento dos determinantes do processo saúde/doença, integralidade da atenção e possibilidades locais.

- É recomendável que a composição das equipes contemple, R. Inter. Interdisc. INTERthesis, Florianópolis, v.5, p. 78-103, jan./jul. 2008. 
minimamente, um médico de família ou generalista, um enfermeiro, um auxiliar de enfermagem e Agentes Comunitários de Saúde (ACS). Estas equipes estarão sempre abertas a novas categorias profissionais em função das demandas e possibilidades locais, sendo responsáveis por uma população adscrita e devendo residir no município, com regime de trabalho de dedicação integral. Os ACSs devem residir na área de abrangência de seu trabalho.

- A atribuição das equipes envolve atividades a serem constantemente avaliadas através do acompanhamento dos indicadores de saúde da área de atuação, devendo as equipes estar preparadas para:

- conhecer a realidade das famílias pelas quais são responsáveis, com ênfase nas suas características sociais, demográficas e epidemiológicas

- identificar os problemas de saúde prevalentes e situações de risco aos quais a população está exposta

- elaborar, com a participação da comunidade, um plano local para o enfrentamento dos determinantes do processo saúde/doença

- prestar assistência integral, respondendo de forma contínua e racionalizada à demanda organizada ou espontânea, com ênfase nas ações de promoção à saúde

- resolver, através da adequada utilização do sistema de referência e contrareferência, os principais problemas detectados

- desenvolver processos educativos para a saúde, voltados à melhoria do autocuidado dos indivíduos

- promover ações intersetoriais para o enfrentamento dos problemas identificados A base de atuação das equipes são as unidades básicas de saúde, incluindo as atividades de:

- visita domiciliar - com a finalidade de monitorar a situação de saúde das famílias. A equipe deve realizar visitas programadas ou voltadas ao atendimento de demandas espontâneas, segundo critérios epidemiológicos e de identificação de risco. O acompanhamento dos Agentes Comunitários de Saúde em microáreas, selecionadas no território de responsabilidade das unidades de Saúde da Família, representa um componente facilitador para a identificação das necessidades e racionalização do emprego dessa modalidade de atenção

- internação domiciliar - não substitui a internação hospitalar tradicional. Deve ser utilizada no intuito de humanizar e garantir maior qualidade e conforto ao paciente. Por isso, só deve ser realizada quando as condições clínicas e familiares do paciente a permitem. A hospitalização deve ser feita sempre que necessária, com o devido acompanhamento por parte da equipe

- participação em grupos comunitários - a equipe deve estimular e participar de reuniões de grupo, discutindo os temas relativos ao diagnóstico e alternativas para a resolução dos problemas identificados como prioritários pelas comunidades. (BRASIL, Ministério..., 1997, p.15-16)

R. Inter. Interdisc. INTERthesis, Florianópolis, v.5, p. 78-103, jan./jul. 2008. 
Quanto à reorganização das práticas de trabalho, o Ministério propõe a necessidade de um diagnóstico da saúde da comunidade e, para tanto, refere-se à diretriz do cadastramento das famílias da área de abrangência e à conseqüente formulação de indicadores epidemiológicos e socioeconômicos que norteariam o planejamento e organização das ações de saúde. Também devem ser utilizadas outras fontes oficiais de dados e da comunidade para a construção deste diagnóstico.

planejamento/programação local baseia-se na idéia de considerar "tanto quem planeja como para quê e para quem se planeja [...] Além disso, o processo de planejamento deve ser pensado como um todo e direcionado à resolução dos problemas identificados no território [...] visando à melhoria progressiva das condições de saúde e de qualidade de vida da população assistida [...] contrapõe-se ao planejamento centralizado" (1997, p.19). Esta forma de planejamento amplia a participação e está em consonância com o enfoque estratégico de planejamento utilizado como referencial na construção do distrito sanitário.

O PSF é um dos componentes das políticas de saúde e as unidades que o implementam organizam-se de forma complementar ao sistema. Neste programa o atendimento deve ser realizado por uma equipe, visando a uma abordagem multiprofissional no enfrentamento dos problemas, de forma enfaticamente preventiva, mas também curativa, com integralidade da atenção, em parceria com a comunidade e dentro das possibilidades locais. Quando da necessidade de encaminhamento para níveis de maior complexidade do sistema de saúde, em respeito ao princípio da integralidade da atenção e hierarquização do sistema, deve formar-se um processo de referência e contra-referência, em que a equipe do PSF permanece como responsável pelo acompanhamento dos indivíduos e famílias.

A educação continuada é um processo de capacitação e informação que permite atender às necessidades de maneira dinâmica e eficaz, possibilitando aperfeiçoamento profissional, desenvolvimento do trabalho de equipe e criação de vínculo com a população. Este processo, respeitando as realidades loco-regionais, deve envolver também as instituições formais de ensino, tais como as universidades ou, até mesmo, educação à distância na capacitação de recursos humanos. A formação em serviço deve ser priorizada.

O estímulo à ação intersetorial deve ser constante, uma vez que os problemas de saúde ou a própria situação sanitária são determinados socialmente e, por sua vez, as R. Inter. Interdisc. INTERthesis, Florianópolis, v.5, p. 78-103, jan./jul. 2008. 
questões sociais tampouco serão resolvidas setorialmente.

O acompanhamento e avaliação das ações devem considerar a realidade local e a participação popular, uma vez que seus resultados não são dados meramente técnicos, mas uma informação que interessa a todos os envolvidos, sejam gestores, profissionais de saúde ou população, sendo fundamental sua ampla divulgação e discussão. Os instrumentos usados na avaliação devem aferir minimamente as reais alterações ocorridas no modelo assistencial, a satisfação do usuário e dos profissionais, a qualidade do trabalho desenvolvido pela equipe e o seu impacto nos indicadores de saúde. Já o acompanhamento e a avaliação da atuação das unidades de Saúde da Família podem ser feitos através da organização de um sistema de informação, de um relatório de gestão e de outros instrumentos a serem definidos pelos gestores municipais e/ou estaduais.

O controle social, que na saúde é entendido como a participação da população na definição, execução, acompanhamento e fiscalização das políticas públicas do setor, é um princípio e uma garantia constitucional regulamentada pela Lei Orgânica de Saúde $n^{\circ}$ 8.142/90. Esta lei definiu, além dos demais fóruns formais e informais, as conferências e os conselhos de saúde, nas três esferas de governo, como próprios para o exercício do controle social.

No referido documento constam ainda os níveis de competência das três esferas de governo, sendo o nível municipal definido como o espaço de execução da estratégia de Saúde da Família e, portanto, responsável por definir a melhor adequação dos meios e condições operacionais para a sua implementação, cabendo-lhe, dessa forma:

- elaborar o projeto de implantação da estratégia de Saúde da Família para a reorientação das unidades básicas de saúde - eleger áreas prioritárias para a implantação do projeto

- submeter o projeto à aprovação do Conselho Municipal de Saúde

- encaminhar o projeto para parecer da Secretaria Estadual de Saúde e Comissão Intergestores Bipartite

- selecionar e contratar os profissionais que comporão a equipe de saúde

- promover, com o apoio da Secretaria Estadual da Saúde, a capacitação das equipes de saúde

- implantar o sistema de informações e avaliação da estratégia de Saúde da Família

- acompanhar e avaliar sistematicamente o desempenho das unidade de Saúde da Família

- inserir o financiamento das ações das unidades de Saúde da Família na programação ambulatorial do município, definindo a contrapartida municipal

R. Inter. Interdisc. INTERthesis, Florianópolis, v.5, p. 78-103, jan./jul. 2008. 
- garantir a infra-estrutura/funcionamento da rede básica necessária ao pleno desenvolvimento das ações da estratégia de Saúde da Família. (BRASIL, Ministério..., 1997, p. 27-28)

A implantação e implementação do Programa de Saúde da Família que o Ministério da Saúde preconiza está fundamentado nos conceitos que norteiam a construção do SUS e, ainda que tenha se inspirado em modelos estrangeiros, assume personalidade própria, em consonância com a lei da saúde no Brasil.

R. Inter. Interdisc. INTERthesis, Florianópolis, v.5, p. 78-103, jan./jul. 2008. 


\section{REFERÊNCIAS}

BRASIL. Ministério da Saúde. (1990) O ABC do SUS. Brasília.

BRASIL. Ministério da Saúde. (1996) Norma operacional básica. Brasília.

BRASIL. Ministério da Saúde. (1997) Saúde da família: uma estratégia para a reorientação do modelo assistencial. Brasília.

BREILH, J. (1991) Epidemiologia: economia, política e saúde. São Paulo: Unesp: Hucitec.

CHAVES, M. M. (1980) Saúde e sistemas. Rio de Janeiro: FGV.

DAL POZ, M. R.; VIANA, A. L. D. (1998) A reforma do sistema de saúde no Brasil e o Programa de Saúde da Família. Physis: Revista de Saúde Coletiva, Rio de Janeiro, v. 8, n. 2, p. 11-48.

DONNANGELO, M. C. F. (1976) Saúde e sociedade. São Paulo: Livraria Duas Cidades.

DUPUY, F. I. (1991) Educación médica y necesidades de salud poblacional. LaHabana, Cuba,.

ESCOREL, S. (1999) Reviravolta na saúde: origem e articulação do movimento sanitário. Rio de Janeiro: Fiocruz.

FACCHINI, L. A. (1994) Por que a doença? : a inferência causal e os marcos teóricos de análise. In: ROCHA, L. E.; RIGOTTO, R. M. (Orgs.). Isto é trabalho de gente? : vida, doença e trabalho no Brasil. Petrópolis: Vozes, p. 56-75.

FERREIRA, S. R. S.; MALERBA, H. ; PIRES, N. (1996) História e avanços do trabalho de enfermagem na Divisão de Saúde Comunitária do Grupo Hospitalar Conceição. GHC: Momento e Perspectivas em Saúde, Porto Alegre, v. 9, n. 2, p. 106-113, jul./dez..

GIACOMINI, C. H. (1992) A regionalização em saúde. Saúde Para Debate, Londrina, n. 8, p. 5963, maio.

GRAMSCI, A. (1974) Obras escolhidas. Lisboa: Estampa, 2 v. (Coleção Teoria ; n. 22).

ÍNTEGRA Relatório Final da $8^{a}$ Conferência Nacional de Saúde. (1989) Espaço Para a Saúde, Curitiba, v. 1, n. 0, p. 44-46.

LEAVELL, H. P. R.; CLARK, E. G. (1976) Medicina preventiva. Rio de Janeiro: McGraw-Hill do Brasil.

MENDES, E. V. (1996) Uma agenda para a saúde. São Paulo: Hucitec.

MENDES, E. V. (Org.). (1995) Distrito sanitário: o processo social de mudança das práticas sanitárias do Sistema Único de Saúde. São Paulo: Hucitec ; Rio de Janeiro: Abrasco.

MERHY, E. E.; FRANCO, T. B. (2003) PSF: contradições de um programa destinado à mudança do modelo tecnoassistencial. In: MERHY, E.E. et al. O trabalho em saúde: olhando e experienciando o SUS no cotidiano. São Paulo: Hucitec.

R. Inter. Interdisc. INTERthesis, Florianópolis, v.5, p. 78-103, jan./jul. 2008. 
NEMES, M. I. B. (1990) Ação programática em saúde: recuperação histórica de uma política de Programação. In: SCHRAIBER, L. B. (Org.). Programação em saúde hoje. São Paulo: Hucitec.

ORTIZ, R. (1983) A procura de uma sociologia da prática. In: ORTIZ, R. (Org.). Bourdieu. São Paulo: Ática. p. 7-36. (Coleção Grandes cientistas sociais).

PAINEL internacional: experiências em Saúdecidades (1995). Espaço Para a Saúde, Curitiba, v. 4, n. 4, p. 23-26, jan.

RIVERA, F. J. U. (Org). (1989) Planejamento e programação em saúde: um enfoque estratégico. São Paulo: Cortez.

ROSEN, G. (1994) Uma história da saúde pública. São Paulo: UNESP.

ROSSER, W. W. (1994) Internacional comparisons in primary care. Transcrição da palestra proferida no Fórum Saúdecidade, em Curitiba, promovido pela Prefeitura Municipal de Curitiba (PMC).

SADER, E.; GENTILI, P. (Orgs.). (1995) Pós-neoliberalismo: as políticas sociais e o estado democrático. Rio de Janeiro: Paz e Terra,.

SILVA JUNIOR, A. G. (1998) Modelos tecnoassistenciais em saúde: o debate no campo da saúde coletiva. São Paulo: Hucitec.

SILVEIRA, C.H. (2006) Algumas considerações a respeito das políticas de saúde no Brasil. In: MACHADO, P.H.B. et all. (org.). Saúde Coletiva: um campo em construção. Curitiba, Ed, IBPEX,. cap. I, p. 31-65.

SILVEIRA, C. H. (2000) Programa de Saúde da Família - um estudo de caso no município de Joinville/SC. [Dissertação de Mestrado], Curitiba: UFPR,.

TARRIDE, M. I. (1998) Saúde pública: uma complexidade anunciada. Rio de Janeiro: Fiocruz,.

TEIXEIRA, F. J. S.; OLIVEIRA, M. A. (Orgs.). (1998) Neoliberalismo e reestruturação produtiva. São Paulo: Cortez; Fortaleza: UECE,.

VAITSMAN, J. (1992) Saúde, cultura e necessidades. In: FLEURY, S. (Org.). Saúde coletiva? : questionando a onipotência do social. Rio de Janeiro: Relume Dumará,.

VASCONCELOS, M. P. C. (1998). Reflexões sobre a saúde da família. In: MENDES, E. V. (Org.). A organização da saúde no nível local. São Paulo: Hucitec, p. 155-172.

Artigo recebido em 29 de abril de 2008. Artigo aceito em 30 de junho de 2008.

R. Inter. Interdisc. INTERthesis, Florianópolis, v.5, p. 78-103, jan./jul. 2008. 